\title{
Treatment of Ingrown Toenail With Proximolateral Matrix Partial Excision and Matrix Phenolization
}

Nezib Karaca, $M D^{1}$

Tugrul Dereli, MD, Prof ${ }^{2}$

'Department of Dermatology, Okmeydani Education and Research Hospital, Okmeydani, Sisli, Istanbul, Turkey

${ }^{2}$ Department of Dermatology, Ege University Medical Faculty, Bornova, Izmir, Turkey

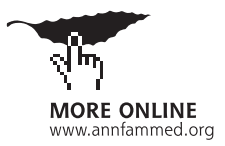

Conflicts of interest: authors report none.

\section{CORRESPONDING AUTHOR}

Nezih Karaca, MD

Department of Dermatology

Okmeydani Education and Research Hospital

34382 Sisli, Istanbul, Turkey

drnezihkaraca@gmail.com

\begin{abstract}
PURPOSE Ingrown toenail is one of the most common nail conditions. Although many surgical treatments are described for complicated cases, recurrence of pain and postoperative disability are common. We evaluated the long-term efficacy of proximolateral matrix partial excision followed by chemical matricectomy with phenol.
\end{abstract}

METHODS We performed 348 proximolateral partial matricectomies and phenol ablations in 225 patients with stage 2 or 3 ingrown toenail. Patients were examined weekly until full wound healing was achieved and were observed for 24 months to assess the long-term efficacy of the treatment.

RESULTS Short-term results were good. We observed only 1 recurrence during the 24-month follow-up period, at 8 months. The success rate was therefore $99.7 \%$. No severe complications occurred. Cosmetic results were remarkably good.

CONCLUSIONS Proximolateral partial matricectomy with phenol ablation is an excellent surgical method for the treatment of ingrown toenails, having low morbidity and a high success rate, even in the long term.

Ann Fam Med 2012;10:556-559. doi:10.1370/afm.1406.

\section{INTRODUCTION}

ngrown toenails caused by compression of the lateral nail edge on the underlying soft tissue is one of the most common nail problems, accounting for $20 \%$ of patients seen by family physicians for foot conditions. ${ }^{1}$ Adolescents and young adults are affected more frequently than other age-groups. Ingrown toenail most often occurs on the big toe, although it can occur on other digits. ${ }^{2}$ An ingrown toenail develops when the proper fit of the nail plate in the lateral nail groove is altered, and several causes (anatomic abnormalities, improperly trimmed nails, poorly fitting shoes, and repetitive trauma) have been suggested. The condition causes discomfort and pain, and restricts activity. ${ }^{3,4}$

A staging system has been developed to grade the severity of ingrown toenails. ${ }^{2,5}$ Stage 1 is characterized by erythema, slight edema, and pain, particularly with pressure. Stage 2 consists of the same symptoms but of greater severity; the wound may become locally infected and start to drain. In stage 3, all signs and symptoms are amplified, and there is associated formation of granulation tissue and lateral nail fold hypertrophy.

Various methods of treating ingrown toenails have been described, ranging from conservative approaches to extensive surgical procedures. ${ }^{6-8}$ The combination of proximolateral partial matricectomy and phenol ablation achieves the lowest recurrence rate and provides the best cosmetic outcome. To the best of our knowledge, this is the first study to assess this technique when performed using a modified version of the Zadik method for matricectomy. We chose this technique as it is more invasive than simple partial nail avulsion and easier to perform than wide wedge excision. 
Also, excising the lateral and proximolateral matrices, in addition to avulsing the nail, and then applying phenol may further reduce the recurrence rate.

\section{METHODS}

Between 2006 and 2010, we performed proximolateral partial matricectomy and phenol ablation in a series of patients with stage 2 or 3 ingrown toenails. Patients with vascular disease and diabetes mellitus were excluded. Our study was approved by the Ege University Hospital Ethics Committee and complied with the principles of the Declaration of Helsinki.

\section{Surgical Technique}

After disinfection of the digits with povidone-iodine solution, we administered digital anesthesia consisting of lidocaine hydrochloride $20 \mathrm{mg} / \mathrm{mL}$ and epinephrine hydrochloride $0.0125 \mathrm{mg} / \mathrm{mL}$ (Supplemental

\section{Figure 1, available at http://annfammed.org/con-}

in tent/10/6/556/suppl/DC1). A finger tourniquet was applied to the digit and clamped. We made a longitudinal incision roughly 7 to $8 \mathrm{~mm}$ extending from the edge of the nail to the distal interphalangeal joint and $3 \mathrm{~mm}$ proximal to the lateral nail fold, but did not raise skin flaps. After dissecting the lateral segment (3 mm) of the plate from the nail bed to the matrix, we cut the nail plate and proximolateral matrix using a side cutter. We removed the nail and matrix using a straight hemostatic forceps (Klemmer or Kelly) and ensured that all matrices over the distal phalanx were cleaned using a

curette (Supplemental Figure 2, available at http://

H annfammed.org/content/10/6/556/suppl/DC1).

We cleaned blood from the surgical field thoroughly using a cotton-tipped swab and then vigorously massaged the matrix for 2 minutes with a cotton-tipped swab dipped in an aqueous solution of $88 \%$ phenol, with rotation directed toward the lateral fold (Supplemental

Figure 3, http://annfammed.org/content/10/6/556/

fin suppl/DC1). Contact of phenol with the surrounding

skin was avoided, and the treated area was carefully washed with $70 \%$ isopropyl alcohol to neutralize any residual phenol. In this way, both the matrix and nail bed on the side of ingrown toenail were excised, and any matrix residues were denatured with phenol.

The wound was closed with one suture $3 \mathrm{~mm}$ under the proximal nail curve and another through the middle of the lateral nail plate. We applied topical antibiotics, and after tourniquet removal, a pressure dressing with a sterile gauze pad that was left in place for 24 hours.

\section{Postoperative Care}

After surgery, patients were given oral nonsteroidal anti-inflammatory drugs for pain control. Older adults were also prescribed oral azithromycin $500 \mathrm{mg} / \mathrm{d}$ for 3 days. Patients were advised to keep the affected foot elevated whenever possible and were taught how to change the dressing and instructed to do so once daily, from the third postoperative day until full wound healing. Any infections of the nail fold were treated using topical antibiotics. Clinical follow-up was performed at $2,4,8$, and 16 weeks, and telephonic follow-up was performed at 1 and 2 years. Recurrence was defined as evidence of ingrowth of the nail edge or spicule formation.

\section{RESULTS}

In all, we treated 348 ingrown toenails in 225 patients (98 male and 127 female) (Table 1 ). The mean age of the patients was $23.8 \pm 8.2$ years. All patients had been previously treated using conservative methods, and 56 had previously been treated with nail avulsion.

We did not record any postoperative complications or complaints about the cosmetic outcome. The healing period ranged from 2 to 4 weeks (Supplemental Figures $4 \mathrm{a}$ and $4 \mathrm{~b}$, available at http://annfammed. org/content/10/6/556/suppl/DC1).

There was only 1 recurrence of ingrown toenail, observed 8 months after treatment. This patient underwent reoperation using the same technique and did not have any further recurrence during 2 years of followup. The success rate after 2 years was thus $99.7 \%$. Telephonic follow-up at 2 years showed that all the patients were satisfied with the cosmetic outcome.

\section{DISCUSSION}

Our results show that partial nail plate avulsion combined with excision of the lateral and proximal nail matrix and followed by phenolic ablation is a suitable surgical method for treating severe ingrown toenails, and is associated with a low recurrence rate and excellent cosmetic results.

\section{Phenolization}

Segmental matrix cauterization with liquefied phenol has been shown to permanently destroy the lateral

\begin{tabular}{|c|c|}
\hline Characteristic & Value \\
\hline Age, mean (SD), y & $23.8(8.2)$ \\
\hline \multicolumn{2}{|l|}{ Sex, No. } \\
\hline Male & 98 \\
\hline Female & 127 \\
\hline Procedures, No. & 348 \\
\hline \multicolumn{2}{|c|}{ Laterality of ingrown toenail, No. } \\
\hline Bilateral & 42 \\
\hline Unilateral & 264 \\
\hline
\end{tabular}


matrix. Phenol $\left(\mathrm{C}_{6} \mathrm{H}_{5} \mathrm{OH}\right)$ is a colorless crystal derived from coal tar. Liquefied phenol (carbolic acid) has antibacterial, anesthetic, and, in its concentrated form, escharotic properties. It acts via denaturation of the matrix and any other soft tissue proteins. ${ }^{7}$

The aim of phenol therapy is chemical destruction of the lateral and proximal horns of the matrix, and prevention of future growth of the lateral nail plate into the proximolateral nail fold. The main contraindications for chemical matricectomy are moderate to severe vascular disease of the foot, factors delaying wound healing, and allergy to the chemical used. ${ }^{8,9}$

\section{Surgical Treatment}

Surgical treatment is the best option available for stage 2 or 3 ingrown nails, as conservative approaches have high rates of failure and recurrence. Many surgical techniques have been proposed (Table 2). Conventional surgical treatment of ingrown toenails has been associated with an unacceptably high recurrence rate, substantial postoperative pain, and poor cosmetic results. ${ }^{10,11}$ Simple nail edge excision has a recurrence rate of $39 \%,{ }^{10,12}$ and total nail avulsion has a recurrence rate of $83 \%,{ }^{13,14}$ whereas soft tissue resection has a cure rate of $60 \% .^{10,14,15}$ The reported recurrence rate after wedge resection ranges from $12 \%$ to $30 \% .^{10,16,17}$

Total nail bed ablation using the Zadik procedure is associated with considerable postoperative pain and recurrence rates ranging from $16 \%$ to $28 \%{ }^{18}$ Moreover, patients, particularly young women, often object to the inadequate cosmetic results. ${ }^{10}$ Excision of the proximolateral matrix segment is effective, and cure rates exceeding $95 \%$ have been reported, but this technique is technically difficult, and the associated overaggressive bone destruction can lead to osseous infection and complications ${ }^{19} ;$ however, if the technique is performed correctly, the risk of complications is very low. None of the patients in our study had evidence of osseous infection during follow-up, nor did any need analgesics beyond postoperative day 3 .

\section{Table 2. Treatment Options for Ingrown Toenails}

Conservative measures:

Push back skinfold

Insertion of a cotton pad under lateral edge of nail plate

Removal (avulsion) of the affected border of the nail plate

Removal (avulsion) of the entire nail plate

Partial or complete removal of nail plate with destruction (ablation) of nail matrix to prevent regrowth using:

Caustic liquid (eg, phenol, sodium hydroxide)

Surgery (wedge excision of nail matrix)

Cryotherapy

Laser
Other nonsurgical treatment choices for destroying the nail matrix have limitations. Cryotherapy is associated with a high recurrence rate $(36 \%) .{ }^{20}$ Newer methods of segmental nail bed ablation, including electrodessication, sodium hydroxide treatment, negative galvanic current therapy, and carbon dioxide laser treatment, provide good results, but are more expensive than phenol ablation..$^{9,21-25}$

\section{Zadik Technique}

In $1950, \mathrm{Zadik}^{18}$ reported a radical surgical technique for treating ingrown toenails, and Fowler ${ }^{26}$ subsequently described in detail use of this technique for bilateral and unilateral ingrown toenails.

For bilateral ingrown toenails (ie, those affecting medial and lateral aspects of the same nail), under local anesthesia and tourniquet control, 2 oblique $1.25 \mathrm{~cm}$ incisions are made, beginning at the junction of the nail fold and nail walls. Three skin-only flaps are dis-

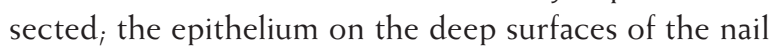
fold and nail walls is left intact. The nail is avulsed and the skin flaps retracted. Sharp dissection is used to remove a block of tissue: the germinal matrix and the overlying deep layer of the nail fold and walls. The skin flaps are then sutured back to cover the wound.

The technique for unilateral ingrown toenail is similar in all essentials to the above operation, except that the excision of the germinal matrix is limited to a wide segment at the corner of the nail. One skin incision is used and 2 flaps are raised to expose the germinal matrix of the affected side of the nail. The wound is completely covered by the skin flaps.

Certain aspects of the technique need emphasis. The operations must be exact dissections to the limits of the germinal matrix. Distally, the matrix is divided just beyond the edge of the lunular area proximally, $^{2}$ the dissection reaches nearly to the joint line; and laterally, it continues until the blade reaches the fatty tissue of the pulp. For total excision of the germinal matrix, the tissue is excised in 2 parts by starting from the midline and working to each side. ${ }^{26}$

Our procedure, described in Methods, differs from the Zadik procedure in its use of a longitudinal incision in the side of ingrown toenail, partial (vs total) extraction of the matrix, and addition of phenol ablation of the nail bed of the ingrown toenail. Excising the lateral and proximolateral matrices, in addition to nail avulsion, and using phenolization might more effectively reduce the recurrence rate.

\section{Comparative Effectiveness of Techniques}

The literature contains many reports of the effectiveness, cure rates, and complications of matrix cauterization with phenol in the treatment of ingrown nails. ${ }^{17,27-30}$ 
A Cochrane review has described the various methods for treating ingrown toenails. ${ }^{31}$ The authors noted that the combination of simple nail avulsion and phenolization was more effective than all other methods. In 2 of the studies reviewed, combination techniques - the Zadik procedure with phenolization, and the Winograd procedure with phenolization-were used in 31 and 170 patients, respectively, whereas other studies compared surgery alone with phenolization. Adding to the studies reported in the Cochrane review, our study had more patients and provides longer-term data on success rate.

Follow-up is key for evaluating treatment of ingrown toenails because recurrence can occur up to 2 years later. We obtained a $99.7 \%$ success rate at 2 years. We believe that our technique, using several treatments in a single procedure, ranks as one of the best for preventing recurrence and achieving a high success rate. We did not have a control group, however. Controlled studies comparing our technique with others are needed to determine which is most efficacious.

In conclusion, partial excision of the proximolateral matrix combined with phenolic ablation for the treatment of ingrown toenails was highly effective and is the treatment of choice at our clinic because of its high success rate in the long term. We believe that the surgical technique is the most important determinant of the success rate. Removing a sufficient width of nail $(3 \mathrm{~mm})$ and appropriate curettage after proximolateral matrix excision are the most critical factors for avoiding nail spicules in the sulcus or under the eponychium, and preventing recurrence after phenol chemical matricectomy.

To read or post commentaries in response to this article, see it online at http://www.annfammed.org/content/10/6/556.

Key words: ingrown toenail; onychocryptosis; unguis incarnatus; surgery; phenol; matricectomy

Submitted September 27, 2011; submitted, revised, January 17, 2012, accepted February 1, 2012.

\section{References}

1. Peyvandi H, Robati RM, Yegane RA, et al. Comparison of two surgical methods (Winograd and sleeve method) in the treatment of ingrown toenail. Dermatol Surg. 2011;37(3):331-335.

2. Zuber TJ, Pfenninger JL. Management of ingrown toenails. Am Fam Phys. 1995;52(1):181-190.

3. Reijnen JA, Goris RJ. Conservative treatment of ingrowing toenails. Br J Surg. 1989;76(9):955-957.

4. Zuber TJ, Pfenninger JL. Management of ingrown toenails. Am Fam Phys. 1995;52(1):181-190.

5. Giacalone VF. Phenol matricectomy in patients with diabetes. J Foot Ankle Surg. 1997;36(4):264-267, discussion 328.

6. Harrer J, Schöffl V, Hohenberger W, Schneider I. Treatment of ingrown toenails using a new conservative method: a prospective study comparing brace treatment with Emmert's procedure. J Am Podiatr Med Assoc. 2005;95(6):542-549.
7. van der Ham AC, Hackeng CA, Yo TI. The treatment of ingrowing toenails. A randomised comparison of wedge excision and phenol cauterisation. J Bone Joint Surg Br. 1990;72(3):507-509.

8. Sykes PA, Kerr R. Treatment of ingrowing nails by surgeons and chiropodists. BMJ. 1988;297(6644):335-336

9. Siegle RJ, Harkness J, Swanson NA. Phenol alcohol technique for permanent matricectomy. Arch Dermatol. 1984;120(3):348-350.

10. Murray WR, Bedi BS. The surgical management of ingrowing toenail. Br J Surg. 1975;62(5):409-412.

11. Palmer BV, Jones $A$. Ingrowing toenails: the results of treatment. Br J Surg. 1979;66(8):575-576.

12. Wallace WA. Gutter treatment for ingrowing toenails. Br Med J. 1979;2(6191):670.

13. Grieg JD, Anderson JH, Ireland AJ, Anderson JR. The surgical treatment of ingrowing toenails. J Bone Joint Surg Br. 1991;73(1):131-133.

14. Cameron PF. Ingrowing toenails: an evaluation of two treatments. Br Med J (Clin Res Ed). 1981;283(6295):821-822.

15. Siegle RJ, Stewart R. Recalcitrant ingrowing nails. Surgical approaches. J Dermatol Surg Oncol. 1992;18(8):744-752.

16. Fulton GJ, O'Donohoe MK, Reynolds JV, Keane FB, Tanner WA. Wedge resection alone or combined with segmental phenolization for the treatment of ingrowing toenail. Br J Surg. 1994;81(7): 1074-1075.

17. Issa MM, Tanner WA. Approach to ingrowing toenails: the wedge resection/segmental phenolization combination treatment. $\mathrm{Br}$ J Surg. 1988;75(2):181-183.

18. Zadik FR. Obliteration of the nailbed of the great toe without shortening the terminal phalanx. J Bone Joint Surg. 1950;32(1):66-67.

19. Haneke E. Surgical treatment of ingrowing toenails. Cutis. 1986; 37(4):251-256.

20. Sonnex TS, Dawber RP. Treatment of ingrowing toenails with liquid nitrogen spray cryotherapy. Br Med J (Clin Res Ed). 1985;291(6489): 173-175.

21. Bostanci S, Ekmekçi P, Gürgey E. Chemical matricectomy with phenol for the treatment of ingrowing toenail: a review of the literature and follow-up of 172 treated patients. Acta Derm Venereol. 2001;81(3):181-183.

22. Ozdemir E, Bostanci S, Ekmekci P, Gurgey E. Chemical matricectomy with $10 \%$ sodium hydroxide for the treatment of ingrowing toenails. Dermatol Surg. 2004;30(1):26-31.

23. Greenwald L, Robbins HM. The chemical matricectomy: a commentary. J Am Podiatry Assoc. 1981;71(7):388-389.

24. Aksakal AB, Akar A, Erbil H, Onder M. A new surgical therapeutic approach to pincer nail deformity. Dermatol Surg. 2001;27(1):55-57.

25. Orenstein A, Goldan O, Weissman O, et al. A comparison between $\mathrm{CO}_{2}$ laser surgery with and without lateral fold vaporization for ingrowing toenails. J Cosmet Laser Ther. 2007;9(2):97-100.

26. Fowler AW. Excision of the germinal matrix: a unified treatment for embedded toe-nail and onychogryphosis. Br J Surg. 1958;45(192):382-387.

27. de Berker DA. Phenolic ablation of the nail matrix. Australas J Dermatol. 2001;42(1):59-61.

28. Noël B. Surgical treatment of ingrown toenail without matricectomy. Dermatol Surg. 2008;34(1):79-83.

29. Ceilley RI, Collison DW. Matricectomy. J Dermatol Surg Oncol. 1992; 18(8):728-734.

30. Thommasen HV, Johnston CS, Thommasen A. The occasional removal of an ingrowing toenail. Can J Rural Med. 2005;10(3): 173-180.

31. Rounding C, Bloomfield S. Surgical treatments for ingrowing toenails. Cochrane Database Syst Rev. 2005;(2):CD001541. 